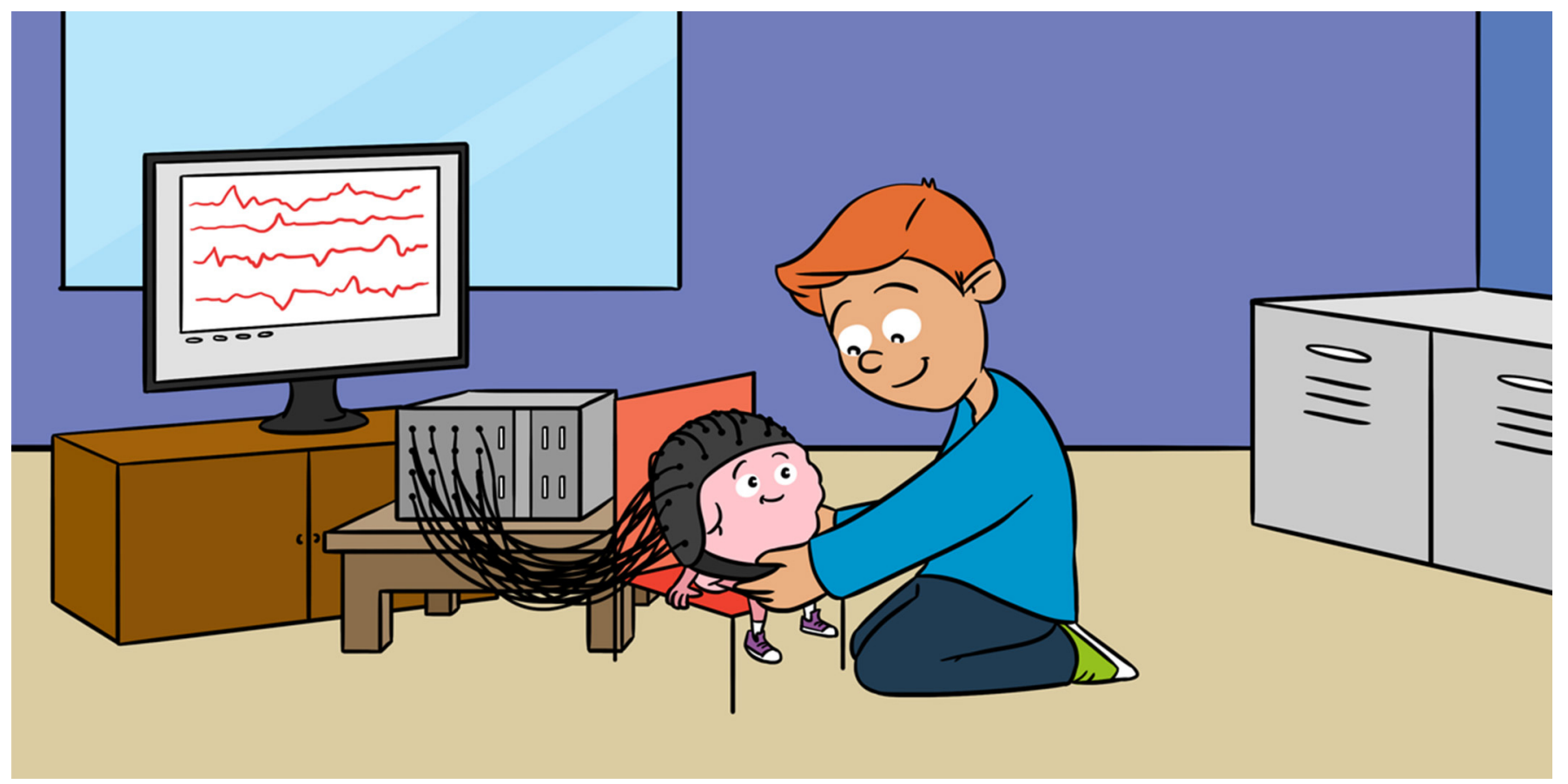

\title{
SHINING LIGHT ON THE BRAIN TO UNDERSTAND HOW IT WORKS
}

\section{Laura Bell ${ }^{1}$, Vanessa Reindl ${ }^{1,2}$, Jana A. Kruppa ${ }^{1,2}$, Alexandra Niephaus ${ }^{1}$, Simon H. Kohl ${ }^{1,2}$ and Kerstin Konrad ${ }^{1,2^{*}}$}

${ }^{1}$ Child Neuropsychology Section, Department of Child and Adolescent Psychiatry, Psychosomatics and Psychotherapy, Medical Faculty, RWTH Aachen University, Aachen, Germany

2JARA-Brain Institute II, Molecular Neuroscience and Neuroimaging (INM-11), RWTH Aachen \& Research Centre Juelich, Juelich, Germany

YOUNG REVIEWERS:

THE

SCHECHTMAN

FAMILY

AGES: 8-13
Have you ever thought that light could tell you something about your brain? Light is a powerful tool that helps brain researchers understand the brain. Our eyes can only see $<1 \%$ of the total light around us. Some of the light is red, so-called near-infrared light. This type of light can travel through the head and the top layers of the brain, and thereby gives researchers important information about brain activity. The technique that uses near-infrared light has a long name: functional near-infrared spectroscopy (fNIRS). In this article, we will show you what a fNIRS machine looks like and what it is like to take part in a fNIRS experiment. We will explain how we can use near-infrared light to better understand the brain. Finally, we will give you some examples of what we use fNIRS for and how it might help children who face difficulties in their daily lives in the long run. 
Figure 1

A boy is connected to a fNIRS machine via a cap. Within the cap are the red and blue fNIRS sensors, the optodes. The red optodes send light into the head and the blue ones receive light. You can see how the near-infrared light travels through the hair, skin, skull, and the brain in a banana-like shape. The wiggly lines on the screen of the fNIRS machine show the changes in the amount of near-infrared light that are detected by the receiving optodes.

\section{FUNCTIONAL}

NEAR-INFRARED SPECTROSCOPY (FNIRS)

A technique that brain researchers use to see whether certain areas of the brain are active.

\section{OPTODE}

A measurement sensor that uses optical information, for example near-infrared light. Optodes can either send or receive light.

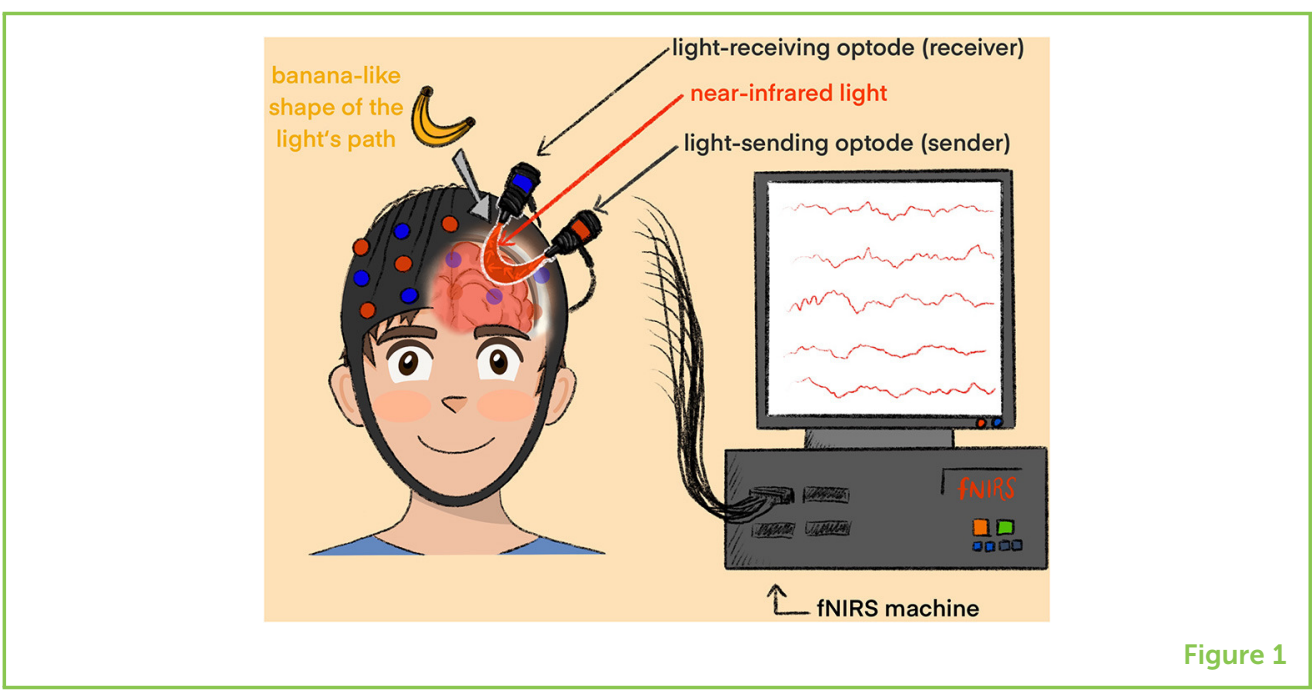

\section{USING LIGHT TO SEE IN THE DARK}

Imagine you want to find out what is hidden in a dark treasure chamber. You cannot see anything due to the darkness. You would probably reach for a flashlight to help you discover what is hiding in the dark chamber. Brain researchers use a similar strategy to see what is going on in a person's brain. The brain is a dark black box, just like the dark treasure chamber. To see inside this black box, brain researchers use a technology called functional near-infrared spectroscopy, or simply fNIRS [1]. The fNIRS machine looks like a computer (Figure 1). Cables with colorful plugs at their ends are connected to this computer. The plugs are the machine's sensors and are called optodes (optical sensors). The red sensors, or senders, send light, like flashlights lighting up the brain. The blue sensors, or receivers, receive light, like eyes seeing what is going on in the brain.

When a person participates in an experiment using fNIRS, the person's hair is brushed aside, and the sensors are placed on the skin of the head. The sensors must remain still, otherwise the signal may be blurred. To keep the sensors from moving, they are often inserted into a cap or fixed with a band around the head. The participant is then asked to do certain things using his/her brain, such as solving math, reading a book, or playing a game, while the fNIRS machine records what happens in the brain.

\section{HOW DOES FNIRS WORK?}

In 1977, Franz Jöbsis was at dinner with his family, when he was astonished to observe that it is possible to shine red light through a bone 3- or 4-mm thick in his beefsteak. Why is that possible? If you look at a rainbow, you can see that light can be broken up into its many component colors, such as violet, blue, green, yellow or red. Each color of light has a different wavelength (Figure 2A). Have you ever 
Figure 2

(A) Each color of light has a specific wavelength. A wavelength describes the distance between the highest points of two waves. (B) Only some wavelengths of light are visible to human eyes and these wavelengths are called visible light. The near-infrared light that the fNIRS machine uses is right between infrared light, which is not visible to human eyes, and red light, which we can see.

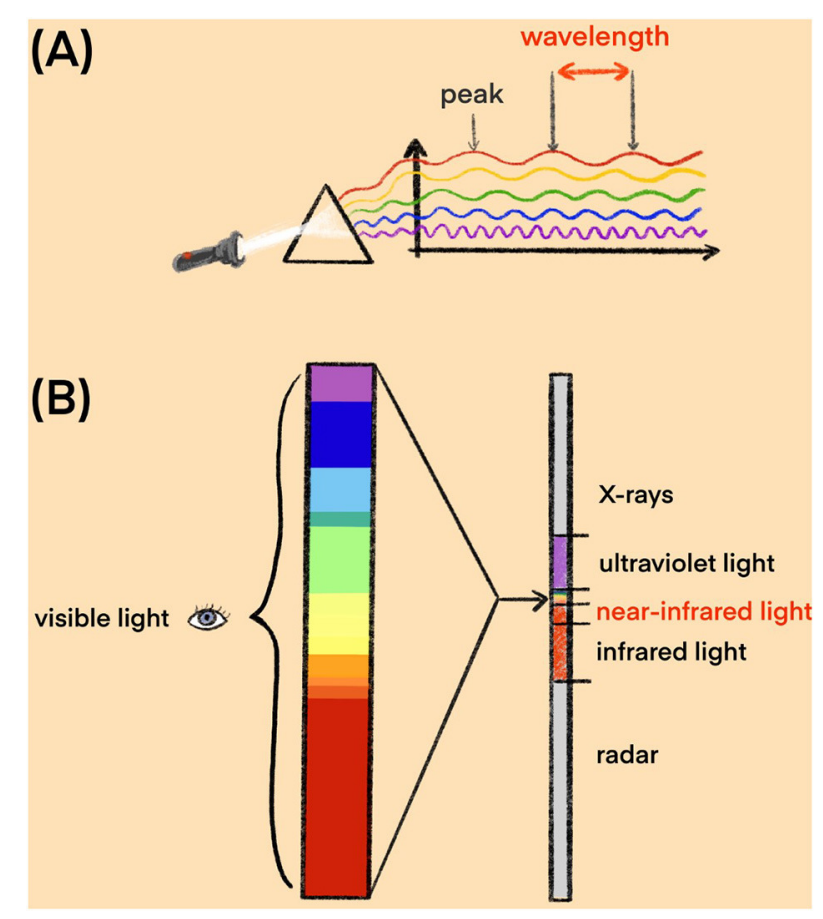

Figure 2

been swimming in the ocean? A wavelength is the distance between the peaks of two light waves, like the distance between two waves in the ocean. The wavelengths of light are measured in nanometers. A nanometer is so small that 1 centimeter contains 10 million of them! Even a hair is about 80,000-100,000 nanometers thick! The red light that Franz Jöbsis used to shine through the bone is the same light a fNIRS machine uses. The light has a wavelength between 650 and 850 nanometers. Light of this wavelength is in what is called the near-infrared spectrum, because it is in between infrared light, which our eyes cannot see, and red light, which is visible to our eyes (Figure 2B). This is where the name "near-infrared spectroscopy" came from. Near-infrared light is harmless to the body. It can shine through biological tissue, like Franz's beefsteak or your brain, quite well.

When the fNIRS sensors are placed on the head, the near-infrared light travels from the senders through several layers, including the skin, the skull, and the protective fluid surrounding the brain, until the light reaches the brain. The path of the light follows a banana-like shape, back to the surface of the head where the receivers are placed (Figure 1). The receivers measure how much of the red light returns to the surface of the head. Not all the light sent into the head returns to the receivers. Why is that? Just like when using your flashlight in the dark treasure chamber, some of the light falls onto objects and changes its path, which is called scattering, while some light travels straight in the direction that you hold the flashlight. Also, on its journey through the different layers of the head, some light is swallowed, or absorbed, by 
Figure 3

(A) Like all other organs, the brain needs oxygen to work. Oxygen travels through the blood vessels attached to a protein called hemoglobin, which is like a backpack carried by red blood cells. The backpack can be either empty or filled with oxygen. (B) Blood vessels widen so that more blood can quickly reach active brain regions, bringing more oxygen. (C) Since hemoglobin attached to oxygen absorbs near-infrared light, active areas of the brain with more oxygenated blood will cause less near-infrared light to arrive at the receiver optodes (red). This tells brain researchers that this brain area must be active.

\section{NEURONS}

Specialized nerve cells in the brain that specialize in communication. Neurons in active parts of the brain need more oxygen.

\section{OXYGEN}

An element that all living beings need to stay alive. Oxygen enters our bodies when we breathe and travels through the body with the help of hemoglobin.

\section{HEMOGLOBIN}

A protein in red blood cells that gives them their red color and allows oxygen to stick to them. Hemoglobin transports oxygen to different parts of the body.

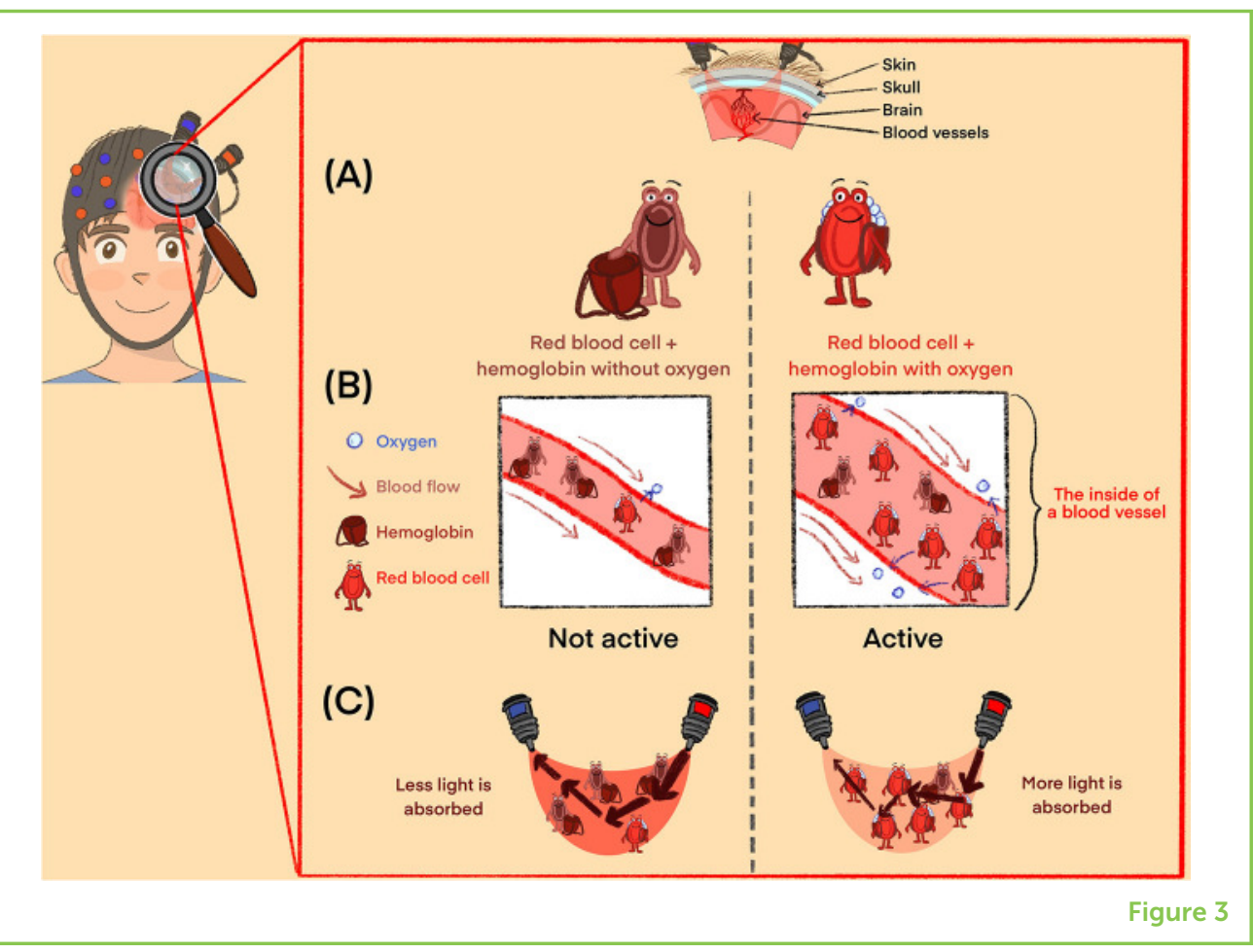

the objects in its way. Light is absorbed by substances in the body such as water, fat, or blood.

\section{HOW DOES FNIRS TELL US ABOUT BRAIN ACTIVITY?}

The brain consists of more than 100 billion cells, called neurons. Like all cells, neurons need oxygen to be active. When you are thinking, some neurons in the brain become active. Therefore, the body sends oxygen-containing blood to the active parts of the brain, to give those areas more energy to help them perform better. This is similar to what happens when you exercise: your body uses more oxygen, so you breathe deeper and more often. Increased breathing allows more oxygen to enter the bloodstream, and the oxygen-rich blood is transported to your working muscles. Oxygen is carried to the places where it is needed by a protein called hemoglobin, which is present inside red blood cells. Hemoglobin is what makes the blood red, and it allows oxygen to stick to red blood cells. You can imagine hemoglobin as a backpack on the red blood cells-it can either contain oxygen or remain empty (Figure $3 \mathrm{~A}$ ). Once the oxygen-containing red blood cells arrive at the active brain regions, they give their oxygen to that brain region, to help it stay active. To help the red blood cells with oxygen-filled backpacks arrive more quickly, the blood vessels near the active brain areas widen (Figure 3B).

You may have noticed that blood is red, but it can have slightly different red colors. The larger blood vessels that you can sometimes see through your skin may even appear blueish. This is because red 
blood cells change color when they have oxygen in their backpacks. Red blood cells with oxygen-filled backpacks have a bright red color, while red blood cells with empty backpacks have a darker red/purple color. How does all this help researchers to see inside the brain? Well, red blood cells with oxygen-filled backpacks absorb more near-infrared light than do non-oxygen-containing blood cells with empty backpacks. When a brain region is active and there are many red blood cells with oxygen-filled backpacks, more of the near-infrared light sent by fNIRS will be swallowed or absorbed by those cells, so the amount of light that makes it back to the receivers will be reduced (Figure 3C).

By subtracting the amount of light detected by the receivers from the amount of light sent by the senders, brain researchers can calculate how much light was absorbed as it traveled through the brain. This tells them about changes in the amount of oxygen-rich blood in that area of the brain. If less light arrives at the receivers, the researchers know that more red blood cells with oxygen-filled backpacks must be in that brain region. And more red blood cells with oxygen-filed backpacks in a brain area means more brain activation in that area! This is how fNIRS can tell researchers which areas of the brain are active. That is a cool "trick," do not you think? However, fNIRS does not allow brain researchers to see everything within the brain. When you use a flashlight in a dark room, the objects closest to you will appear most clearly. Similarly, since the fNIRS sensors are placed on the outside of the head, brain researchers can only see what is going on in the outer surface of the brain.

\section{HOW CAN FNIRS HELP CHILDREN?}

Our brains support us in all our daily activities. There is no single activity that we do not need our brains for, even sleep! Simply by reading this article, regions of your brain are activated at this very moment. If you were connected to a fNIRS machine, we could see which areas of your brain are involved in reading. Similarly, fNIRS machines can be used to monitor almost all our daily activities, to find out which brain areas are needed for each. fNIRS can be used for research in children and even babies. Children who have difficulties with attention, math, speech or reading can also take part in fNIRS experiments, and we can use fNIRS to investigate the brains of children who have trouble hearing or making friends [2,3]. Brain researchers are interested in understanding why the brains of some children with difficulties react

NEUROFEEDBACK

\section{TRAINING}

A training that helps you regulate your brain activation by showing it to you live on a computer screen. differently in certain situations. This might help brain researchers to understand certain difficulties better and to develop treatments to help children who suffer from such difficulties in the long run.

FNIRS might even help us to train the brains of children, to help them overcome their difficulties. This is called neurofeedback training (to find out more about neurofeedback training, read this Frontiers for 
Young Minds article) [4]. It involves measuring a person's brain activity and showing it to him or her live, on a computer screen. The person then tries to activate his/her brain a little more with his/her thoughts and imagination, and he/she can see on the screen if he/she is successful. This is like playing a game with the brain: you win when you activate your brain! Researchers are developing these kinds of games for children who have difficulties with attention and concentration. In some of these games, children might be racing a car with their brain activity or trying to launch a rocket. By playing the games, they train the brain areas that help them to concentrate.

\section{ARE YOU ENLIGHTENED?}

So, because active brain regions need oxygen and near-infrared light is absorbed differently by red blood cells with oxygen than by red blood cells without oxygen, researchers can use light to find out whether a brain region is active. fNIRS offers many opportunities for understanding the brain. Further research will hopefully help researchers better understand our fascinating brains, which may allow them to find better ways to help children who face difficulties in their daily lives. If you would like to find out more about the advantages and limitations of fNIRS, check out this article by Soltanlou \& Artemenko [5], which describes how fNIRS can be used to understand how the brain works in the classroom and during many more activities. If you would like to see a video about the way fNIRS works and some examples of what we can use fNIRS for, click on the following link: https://www.youtube.com/watch?v=UCOgoboRE2k (Video 1). We are excited to see what else researchers can find out about the brain! Maybe you will join us 1 day?

\section{ACKNOWLEDGMENTS}

We would like to thank all children and adolescents who stimulated the writing of the current manuscript by asking interesting questions about our brains and how brain imaging works. The fNIRS machine described here was purchased by the University Hospital RWTH Aachen (Germany). Funding for the fNIRS machine described here was provided by a grant of the German Research Foundation (DFG) (INST 206 948/18-1 FUGG), awarded to KK.

\section{REFERENCES}

1. Pinti, P., Tachtsidis, I., Hamilton, A., Hirsch, J., Aichelburg, C., Gilbert, S., et al. 2020. The present and future use of functional near-infrared spectroscopy (fNIRS) for cognitive neuroscience. Ann. N. Y. Acad. Sci.

1464:5-29. doi: 10.1111/nyas. 13948 
2. Bell, L., Scharke, W., Reindl, V., Fels, J., Neuschaefer-Rube, C., and Konrad, K. 2020. Auditory and visual response inhibition in children with bilateral hearing aids and children with ADHD. Brain Sci. 10:307. doi: 10.3390/brainsci10050307

3. Kruppa, J. A., Reindl, V., Gerloff, C., Weiss, E. O., Prinz, J., Herpertz-Dahlmann, B., et al. 2020. Brain and motor synchrony in children and adolescents with ASDan fNIRS hyperscanning study. Soc. Cogn. Affect. Neurosci.

16:103-16. doi: 10.1093/scan/nsaa092

4. Bado, P., Stewart, M., and Moll, J. 2016. Training your emotional brain: from science fiction to neuroscience. Front. Young Minds 4:21. doi: 10.3389/frym.2016.00021

5. Soltanlou, M., and Artemenko, C. 2020. Using light to understand how the brain works in the classroom. Front. Young Minds 8:88. doi: 10.3389/frym.2020.00088

SUBMITTED: 25 June 2020; ACCEPTED: 30 July 2021;

PUBLISHED ONLINE: 27 August 2021.

EDITED BY: David L. Sheinberg, Brown University, United States

CITATION: Bell L, Reindl V, Kruppa JA, Niephaus A, Kohl SH and Konrad K (2021) Shining Light On The Brain to Understand How It Works. Front. Young Minds 9:576211. doi: 10.3389/frym.2021.576211

CONFLICT OF INTEREST: SK has received payments to consult with the start-up company Mendi innovations AB, Stockholm, Sweden. LB has created paid illustrations for NIRx Medizintechnik GmbH, Berlin, Germany.

The remaining authors declare that the research was conducted in the absence of any commercial or financial relationships that could be construed as a potential conflict of interest.

COPYRIGHT @ 2021 Bell, Reindl, Kruppa, Niephaus, Kohl and Konrad. This is an open-access article distributed under the terms of the Creative Commons Attribution License (CC BY). The use, distribution or reproduction in other forums is permitted, provided the original author(s) and the copyright owner(s) are credited and that the original publication in this journal is cited, in accordance with accepted academic practice. No use, distribution or reproduction is permitted which does not comply with these terms.

\section{YOUNG REVIEWERS}

THE SCHECHTMAN FAMILY, AGES: 8-13

We are Ori, Mika, Roni, and Alona-a group of cousins living in Tel-aviv and Gedera, Israel. We enjoy meeting for Friday-night dinner at our grandma's house. We each have different hobbies and fields of interest, but what we do have in common is our love for both hiking and science. 


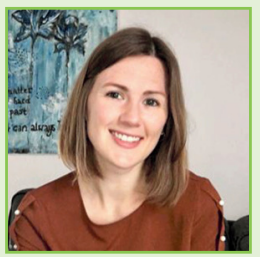

\section{AUTHORS}

\section{LAURA BELL}

I am a brain researcher who conducts studies with fNIRS and I am fascinated by how the brain learns to process what we see, hear, smell, or feel and how the brain can adjust itself when we lose one sense, such as hearing. Is not it crazy that the brain tries to compensate for a lost sense and can even use the input from external listening devices such as cochlear implants and hearing aids? Besides research, I love being outside, doing sports, and drawing-for example, illustrations for this article.
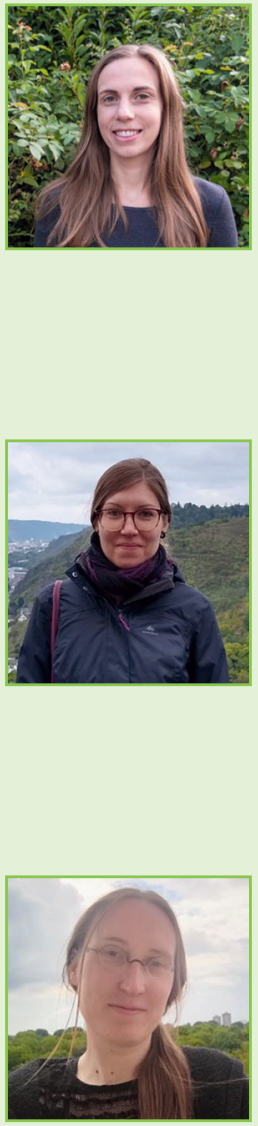

\section{VANESSA REINDL}

In my research I study what happens in the brain and in the body when parents and children play together, using methods like functional near-infrared spectroscopy. To investigate this, we measure the brain activities of parent and child at the same time. It is fascinating to see that when we interact or communicate with each other, our brain activities are in sync, just as you may synchronize your footsteps when you walk next to your friend. Besides research, I enjoy spending time outdoors, going jogging, hiking, or skiing in the winter.

\section{JANA A. KRUPPA}

In my work as a brain researcher, I investigate brain activity and behavior of children, adolescents, and young adults who encounter difficulties in their everyday lives. For example, they may struggle to interact or communicate with others or to concentrate for long periods of time. With my work, I hope to contribute to the development of better treatment methods for these individuals. Besides research, I enjoy spending time with friends, doing yoga, and riding my road bike. I love animals, spending time with my two cats, and being in nature.

\section{ALEXANDRA NIEPHAUS}

I am a brain researcher and also a speech and language therapist. This means that I am very interested in brain function during communication. fNIRS is a perfect tool for that because you can investigate people in situations close to everyday life, and you can also measure more than one person at the same time (hyperscanning). Mostly, I research brain activation in people who stutter or whose speech is way too fast and hard to understand. Apart from doing brain research, I really enjoy playing adventure games on the computer or playing card and board games with my friends.

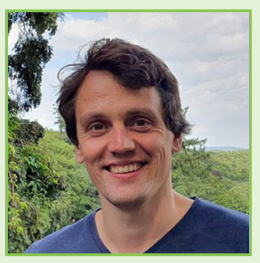

\section{SIMON H. KOHL}

I am a psychologist and neuroscientist. I am very fascinated by neurofeedback, a form of brain training in which people can look at their own brain activity in real-time and learn how to control it. How does the brain learn to regulate itself? Can we use neurofeedback to change brain functions and eventually improve people's lives, or is it just hype? For this purpose, I am currently working with fNIRS, which is a great tool because it is so easy to use. Besides neuroscience and psychology, I am a passionate martial artist, and love to spend my time outside and meet friends.

\section{KERSTIN KONRAD}

I am a professor of clinical child neuropsychology at the RWTH Aachen University/Germany and the Research Center Juelich. I study how the brain develops 
from infancy to young adulthood and what happens if brain development goes awry. With my work, I hope to help children who experience difficulties at school, or with their families or friends, to feel better, to better concentrate, and to improve their emotion regulation and well-being! Brain research with and for children is the most fascinating job I can imagine. *k.konrad@afz-juelich.de 